\title{
The Efficacy of Proton Pump Inhibitor in Cirrhotics with Variceal Bleeding: A Systemic Review and Meta-Analysis
}

\author{
Lin Lin $^{a}$ Binxin Cui ${ }^{a}$ You Deng $^{b}$ Xihui Jiang ${ }^{c}$ Wentian Liu ${ }^{b}$ Chao Sun ${ }^{a} b$ \\ ${ }^{a}$ Department of Gastroenterology, Tianjin Medical University General Hospital Airport Hospital, Tianjin, China; \\ ${ }^{b}$ Department of Gastroenterology and Hepatology, Tianjin Medical University General Hospital, Tianjin, China; \\ ${ }^{c}$ Digestive Medicine Center, The Seventh Affiliated Hospital, Sun Yat-sen University, Shenzhen, China
}

\section{Keywords}

Proton pump inhibitor · Gastroesophageal variceal

bleeding $\cdot$ Re-bleeding rate $\cdot$ Mortality

\begin{abstract}
Background and Aims: Proton pump inhibitor (PPI) was widely used in cirrhotic patients with variceal bleeding empirically rather than evidence-based practice. We aimed to evaluate the plausible indication of PPI use in variceal bleeding cirrhotic patients and figure out whether it can decrease the re-bleeding rate after endoscopic therapy. Furthermore, we also investigated the association between PPI and bleeding-related mortality in these patients. Methods: We have searched in PubMed, Medline, Web of Science, Google Scholar, Cochrane and Embase prior to May 2019. Pooled OR and $95 \% \mathrm{Cl}$ were calculated by random-effects model. $\boldsymbol{R e}$ sults: A total of 11 original articles including 1,818 cirrhotic patients were analyzed. The overall meta-analysis highlighted that PPI use may decrease the re-bleeding rate after endoscopic therapy (OR $0.52,95 \% \mathrm{Cl} 0.35-0.77)$. The conclusion was irrespective of study methods, endoscopic purpose and hemorrhage sites. However, the conclusion speculated that PPI should be prescribed $>1$ month. Meanwhile, PPI use may not impact the bleeding-related mortality. Conclusions: $\mathrm{PPI}$, used for $>1$ month, can decrease re-bleeding rate
\end{abstract}

after endoscopic therapy in cirrhotic patients for prophylaxis or emergency treatment purpose. No matter how long it takes, PPI use is not associated with bleeding-related mortality.

(c) 2020 S. Karger AG, Base

\section{Introduction}

Esophagogastric variceal bleeding (EGVB) is one of the most common and fetal complications occurring in cirrhotic patients. As for acute EGVB, the first-line therapy is endoscopic hemostasis combined with pharmacologic treatment $[1,2]$. Endoscopic hemostasis, mainly including endoscopic variceal ligation (EVL), gastric variceal obliteration (GVO) and sclerotherapy, has achieved a high success rate nowadays; however, post-procedural re-bleeding has been taken into consideration gradually. Life-threatening post-ligation ulcer bleeding occurs in $2-5 \%$ of cirrhotic patients who underwent EVL $[3,4]$. Due to ischemia and acid reflux, esophageal ulceration often develops after EVL procedure, which might cause secondary bleeding [5]. As we known, proton pump in-

\section{L.L. and B.C. contributed equally to this work.}

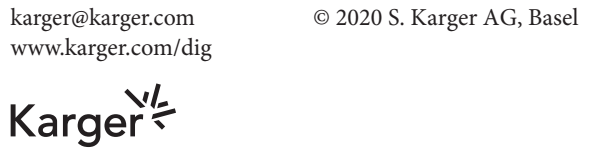

Wentian Liu and Chao Sun, MD, PhD

Department of Gastroenterology and Hepatology Tianjin Medical University General Hospital Anshan Road 154, Heping, Tianjin 300052 (China)

E-Mail tliu01@tmu.edu.cn and chaosun@tmu.edu.cn 
hibitor (PPI) is widely used in the department of gastroenterology considering its potent antacid efficacy. However, the indication of PPI administration during EGVB remains unclear. Guidelines did not indicate whether PPI should be used in patients with acute variceal hemorrhage. Furthermore, British guideline in 2015 has clearly stated that PPI is not recommended in this situation except for existing peptic ulcer [2]. However, there are still many physicians using PPI or $\mathrm{H}_{2}$ receptor inhibitor in patients with variceal hemorrhage. Several studies demonstrated that PPI can delay re-bleeding episode or reduce early bleeding risk after endoscopic hemostasis, and also minimize ulcer sizes through acid suppression and promoting ulcer healing process [6-9]. In contrary, some other reports showed that PPIs were not effective for rebleeding prophylaxis or treatment $[10,11]$. Meanwhile the conclusion of whether PPI could reduce mortality also remains elusive. After searching for related literatures, we found only 3 meta or systemic reviews concerned about the role of adjuvant PPI in EGVB [12-14]. Lodato et al. [13] figured out that PPI overuse in cirrhotics may be empirical rather than evidence-based practice. Meanwhile, the previous works of Lo and Lodato [12, 13] just systematically reviewed the published data but without synthesized them. Although Zhu et al. [14] have investigated this issue with 9 articles involved; they enrolled conference abstract, which may decrease data quality.

In this study, we aimed to evaluate the role of PPI in patients with EGVB. Furthermore, we also analyzed the association between PPI and bleeding-related mortality in these patients.

\section{Methods}

\section{Search Strategy}

The systematic review and meta-analysis was adhered to the PRISMA statement and was registered in the PROSPERO international prospective register of systematic reviews (CRD42019139073). A search of PubMed, Medline, Web of Science, Google Scholar, Cochrane and Embase was conducted. This search was performed in May 2019. Language was limited to English because of our language limitation.

The search terms were as follows: (proton pump inhibitor OR $\mathrm{H}_{2}$ receptor inhibitor OR acid suppression therapy) AND (variceal band ligation OR endoscopic variceal ligation OR sclerotherapy) AND (esophageal varices OR gastroesophageal varices OR variceal hemorrhage OR variceal bleeding).

\section{Inclusion and Exclusion Criteria}

Two reviewers (L.L. and B.C.) screened the titles and abstracts of the literature from the electronic databases independently using the following inclusion criteria to identify all eligible studies: (1) original articles with full text; (2) assessed the association between PPI use and EGVB in cirrhotic patients; (3) including patients $>18$ years old; (4) re-bleeding or bleeding-related death were evaluated as endpoints; (5) the value of OR with $95 \%$ CIs, or raw data were available for the comparison of PPI use and endpoints. We selected adjusted estimates for analyzing if possible, otherwise the raw data was used by calculating the unadjusted effect estimates.

Exclusion criteria were as follows: (1) conference abstracts without full texts or unpublished papers, (2) articles were duplicate publications, reviews, letters, commentaries, editorials, (3) no control group involved, (4) involving non-adult, (5) experimental studies, (6) other language except English. All disagreements were solved by discussion or consultation with the corresponding author (C.S.).

\section{Data Extraction and Outcome Assessment}

Two investigators (L.L. and B.C.) extracted the data independently by reading the full texts involved. Data extraction included author; publication year; country; study design; grade of evidence; clinical characteristics; inclusion and exclusion criteria; intervention and comparison; death or mortality; side effects such as ulcer size, ulcer healing time; doses and duration of PPI and follow-up. Any disagreements or discrepancies were resolved in consensus.

\section{Quality Assessment}

The quality of enrolling studies was assessed independently by 2 authors (Y.D. and X.J.). Observational articles like cohort study or case-control study were evaluated by Newcastle-Ottawa Scale (NOS) [15], which was measured according to the following parameters: selection, comparability, and exposure/outcome. The maximum of NOS was 9 points, and $>6$ point was determined as high-quality, otherwise, as low-quality.

The quality of randomization controlled trial (RCT) was assessed by the Cochrane Risk of Bias Tool [16]. The tool was consistent in 7 particular domains, sequence generation, allocation concealment, blinding of participants and personnel, blinding of outcome assessment, incomplete outcome data, selective outcome reporting, and other bias. Any disagreement was solved by consensus.

\section{Statistical Analysis}

Stata software, version 14 (Stata Corporation, College Station, TX, USA) was used for data analysis. Estimates like pooled OR and 95\% CIs were chosen for meta-analysis. We would choose adjusted estimate value for meta-analysis if possible. Otherwise the raw data was used by calculating the unadjusted effect estimates. We used a random effects model for conservative consideration. Statistical heterogeneity was performed by using $I^{2}$ statistic. An $I^{2}$ value of $<25 \%$ was considered to be low heterogeneity, while $>75 \%$ was considered high heterogeneity, the value between 25 and $75 \%$ was considered moderate [17]. And we considered a $p<0.05$ to indicate the presence of heterogeneity. The test for overall effect of meta-analysis was performed by a $\mathrm{Z}$ value with $p<0.05$, which was considered to be statistically significant. We generated funnel plots and used Egger's asymmetry test [18] for publication bias assessment. A threshold of $p<0.1$ was considered that publication bias existed. If asymmetry was detected, we would evaluate the potential effect of publication bias by using the nonparametric "trimand-fill" test to recalculate the effect size. 
Fig. 1. Results from literature search for studies relating to PPI and gastroesophageal variceal bleeding published prior to May 2019.

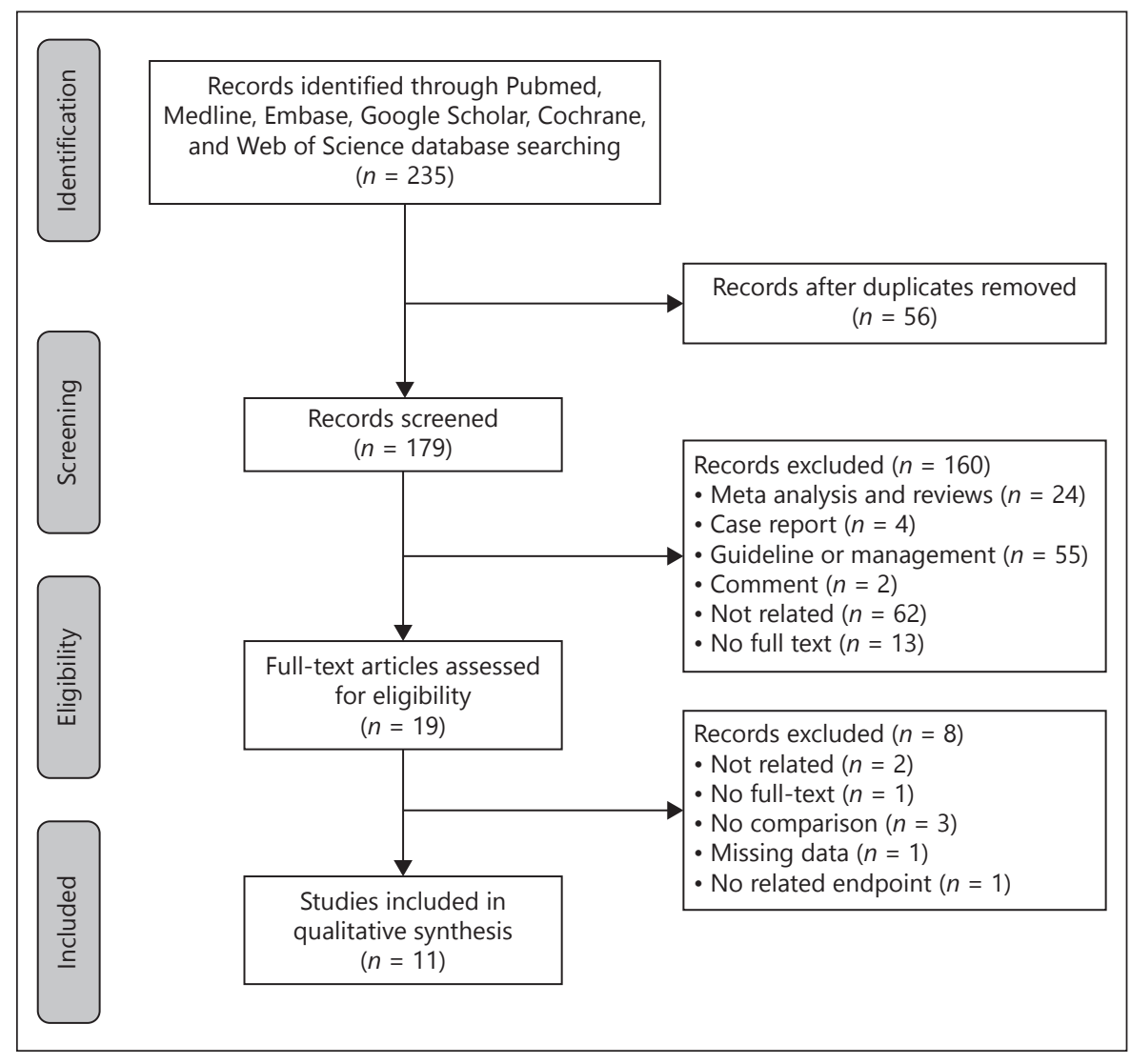

\section{Results}

\section{Study Characteristics and Quality}

We have searched 235 publications which involving PPI and endoscopic therapies in EGVB in electric databases. After discarding 56 duplicate publications and 160 articles which did not meet our requirements, we reviewed the remaining 19 original articles thoroughly. We discarded 2 non-related articles, 3 articles published in 90 's which without comparison, 1 was poster without full text, 1 missed necessary data and 1 was lack of related endpoint. Finally, eleven original researches including 1,818 cirrhotic patients were identified in our analysis [611, 19-23] (Fig. 1).

The main material and clinical characteristics of the included studies were documented in Table 1. Most patients involved in separate studies were elderly male. The proportion of male patients ranged from 45.7 to $81.5 \%$. The re-bleeding rate after endoscopic therapy was $16.3 \%$, 310 patients (17.5\%) died during follow-up period. Among 11 researches, there were 4 articles designed as RCTs, 4 retrospective cohort studies, the remaining 3 were retrospective case-control studies. There were 6 ar- ticles concerned about esophageal varices bleeding by performing EVL for treatment or prophylaxis, and 4 researches clearly identified to perform sclerotherapy or GVO for gastric variceal bleeding. Only one of them did not mention the related endoscopic therapy in their study [11]. Nine out of 11 researches were published by Asian, especially in South Korea and Japan.

Meanwhile, there were 9 of 11 articles unveiling the relationship between PPI and post-procedural-related rebleeding rate. And 6 of 11 researches explored the impact of PPI on the mortality of cirrhotic patients with gastroesophageal varices.

The assessment of study quality was conducted in all eligible researches. Most of studies (8 out of 11) have moderate quality. Five out of 7 observational studies have quality according to NOS. Meanwhile, 3 out of 4 RCTs were acceptable by Cochrane Collaboration tool assessment (Fig. 1).

\section{Meta-Analysis}

Association between PPI and Post-Procedural-

Related Re-bleeding Rate

The meta-analysis revealed that routinely using PPI after endoscopic therapy for EGVB was a protective fac- 
Table 1. Characteristics of the included studies in the current meta-analysis

\begin{tabular}{|c|c|c|c|c|c|c|c|c|c|c|}
\hline \multirow[t]{2}{*}{ Study, year } & \multirow[t]{2}{*}{ Country } & \multirow[t]{2}{*}{ Design } & \multirow[t]{2}{*}{ Number } & \multirow{2}{*}{$\begin{array}{l}\text { Male, } \\
n(\%)\end{array}$} & \multirow[t]{2}{*}{ Age, years } & \multirow{2}{*}{$\begin{array}{l}\text { Endoscopic } \\
\text { therapy }\end{array}$} & \multirow[t]{2}{*}{ Intervention group } & \multirow[t]{2}{*}{ Control group } & \multicolumn{2}{|c|}{ Grade of evidence } \\
\hline & & & & & & & & & NOS & $\begin{array}{l}\text { cochrane risk } \\
\text { of bias tool }\end{array}$ \\
\hline $\begin{array}{l}\text { Wu et al. } \\
{[22], 2017}\end{array}$ & $\begin{array}{l}\text { Taiwan, } \\
\text { China }\end{array}$ & $\mathrm{RC}$ & 637 & $471(73.9)$ & $\begin{array}{l}\text { Intervention } \\
\text { group: } \\
58.84 \pm 16.97 \\
\text { control group: } \\
58.94 \pm 16.57\end{array}$ & EVL & $\begin{array}{l}\text { Vasoconstrictors }+ \\
\mathrm{PPI} / \mathrm{H}_{2} \mathrm{RA}\end{array}$ & $\begin{array}{l}\text { Vasoconstrictors } \\
\text { only }\end{array}$ & 8 & \\
\hline $\begin{array}{l}\text { Cho et al. } \\
{[10], 2017}\end{array}$ & South Korea & $\mathrm{CC}$ & 430 & $363(84.4)$ & $59.5 \pm 11.1$ & EVL & $\begin{array}{l}\text { Vasoconstrictors }+ \\
\text { pantoprazole } \\
40 \mathrm{mg} \times 3 \text { day }+ \\
\text { antibiotics }+ \text { EVL }\end{array}$ & NA & 5 & \\
\hline $\begin{array}{l}\text { Kang et al. } \\
{[19], 2016}\end{array}$ & South Korea & $\mathrm{RC}$ & 505 & $388(76.8)$ & $53.6 \pm 10.58$ & EVL & Standard dosage of PPI & No PPI & 8 & \\
\hline $\begin{array}{l}\text { Lo et al. } \\
{[9], 2013}\end{array}$ & $\begin{array}{l}\text { Taiwan, } \\
\text { China }\end{array}$ & RCT & 118 & $98(83.1)$ & $\begin{array}{l}\text { PPI group: } \\
54.2 \pm 9.7 \\
\text { Vasoconstrictor } \\
\text { group: } 52.5 \pm 14.4\end{array}$ & EVL & $\begin{array}{l}\text { Omeprazole/pantoprazole } \\
40 \mathrm{mg} \text { intravenously } \\
\text { per day during } \\
\text { hospitalization and } \\
\text { pantoprazole } 40 \mathrm{mg} \text { oral } \\
\text { per day } \times 10 \text { days }\end{array}$ & $\begin{array}{l}\text { Vasoconstrictors } \\
\text { (somatostatin } \\
\text { or terlipressin) }\end{array}$ & & $\mathrm{C}$ \\
\hline $\begin{array}{l}\text { Hidaka et al. } \\
{[6], 2012}\end{array}$ & Japan & RCT & 43 & $22(51.0)$ & $61(55-70)$ & EVL & Rabeprazole oral 10 mg/day & No PPI & & B \\
\hline $\begin{array}{l}\text { Shaheen et al. } \\
{[21], 2005}\end{array}$ & USA & RCT & 42 & $24(57.1)$ & 50.5 & EVL & Pantoprazole 40 mg/day & No PPI & & A \\
\hline $\begin{array}{l}\text { Garcia } \\
\text { Saenz-de-Sicilia } \\
\text { et al. [11], } 2010\end{array}$ & México & $\mathrm{RC}$ & 105 & $48(45.7)$ & $58(26-87)$ & Not mention & $\begin{array}{l}\text { Omeprazole } 20 \mathrm{mg} / \text { day } \\
\text { (or an equivalent dose } \\
\text { of any other PPI) }\end{array}$ & No PPI & 7 & \\
\hline $\begin{array}{l}\text { Garg et al. } \\
{[23], 1995}\end{array}$ & India & RCT & 44 & $33(75.0)$ & $\begin{array}{l}\text { Intervention } \\
\text { group: } \\
42.90 \pm 16.81 \\
\text { control group: } \\
29.10 \pm 15.92\end{array}$ & Sclerotherapy & Omeprazole $20 \mathrm{mg} /$ day & No PPI & & $\mathrm{B}$ \\
\hline $\begin{array}{l}\text { Kim et al. } \\
{[8], 2015}\end{array}$ & South Korea & $\mathrm{CC}$ & 341 & $278(81.5)$ & $57.79(22-96)$ & GVO & $\begin{array}{l}\text { PPI + antibiotics + } \\
\text { vasoactive drugs }\end{array}$ & $\begin{array}{l}\text { Antibiotics }+ \\
\text { vasoactive drugs }\end{array}$ & 6 & \\
\hline $\begin{array}{l}\text { Jang et al. } \\
{[7], 2014}\end{array}$ & South Korea & $\mathrm{RC}$ & 16 & $9(56.3)$ & $61.8 \pm 11.7$ & GVO & PPI full dosage orally & No PPI & 5 & \\
\hline $\begin{array}{l}\text { Komori } \\
\text { et al. [20], } 2017\end{array}$ & Japan & $\mathrm{CC}$ & 42 & $29(69.0)$ & $64.9(48-62)$ & GVO & Not mention & Not mention & 6 & \\
\hline
\end{tabular}

RC, retrospective cohort study; CC, case-control study; RCT, randomization controlled trial; EVL, esophageal variceal ligation; GVO, gastric variceal obliteration; PPI, proton pump inhibitor; $\mathrm{H}_{2} \mathrm{RA}, \mathrm{H}_{2}$ receptor inhibitor; NOS, Newcastle-Ottawa Scale.

tor, with a pooled OR 0.52 (95\% CI $0.35-0.77, \mathrm{Z}=3.21$, $p=0.001)$. The heterogeneity was moderate $\left(I^{2} 35.3 \%, p=\right.$ 0.135). In the other words, using PPI after endoscopic therapy may reduce almost $50 \%$ re-bleeding rate in cirrhotics with variceal bleeding.

Because different procedures would be performed for variceal bleeding arising from different sites, while the postoperative re-bleeding rate tend to be higher in gastric variceal bleeding. We subsequently sub-analyzed the data according to esophageal and gastric varices. Both of them supported the conclusion that PPI use after EVL or GVO can reduce the re-bleeding rate (pooled OR 0.43 [0.22-
0.82 ] vs. 0.52 [0.35-0.85]; Fig. 2a). Studies involving esophageal varices have a higher heterogeneity than gastric ones ( $I^{2} 58.2$ vs. $\left.0 \%\right)$.

No matter the purpose for endoscopic therapy was prophylaxis or urgent hemostasis, patients administrated with PPI had a significantly lower risk of re-bleeding. The efficacy was more effective in prophylaxis studies in particularly (pooled OR 0.29 [0.09-0.88] vs. 0.59 [0.420.83]; Fig. 2b). The heterogeneity was 59.9 and $0 \%$ respectively.

We also analyzed the result based on research design methods. Both observational researches and RCTs identi- 


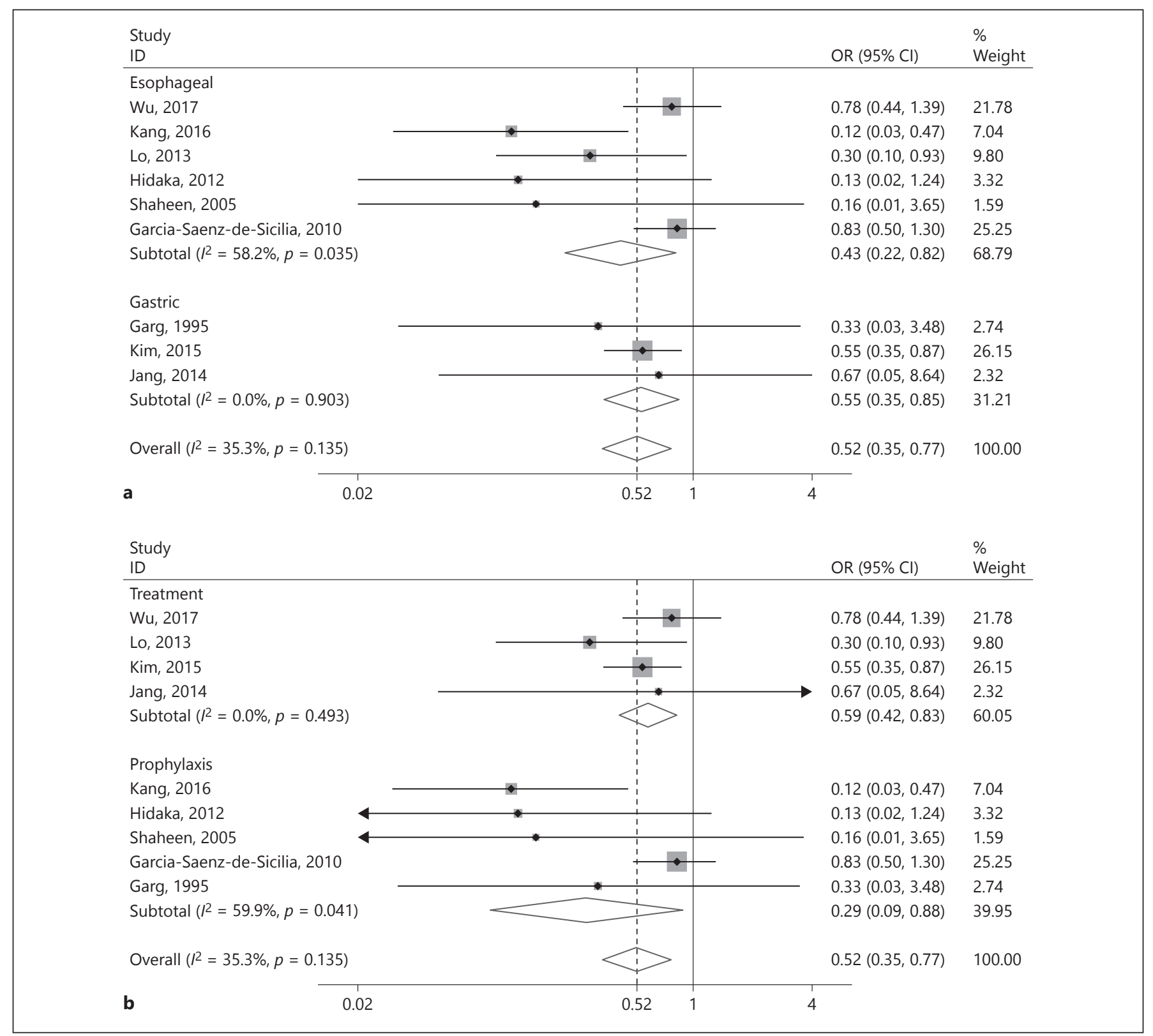

Fig. 2. Forest plots and funnel plot of PPI administration after endoscopic therapy in cirrhotics with gastroesophageal variceal bleeding. The overall meta-analysis revealed that routinely using PPI after endoscopic therapy for variceal bleeding was a protective factor. a Sub-analysis classified with hemorrhage sites. b Sub-analysis depended on prophylaxis or emergency treatment purpose.

fied a significant difference in PPI use and re-bleeding rate (pooled OR $0.61[0.39-0.94]$ vs. $0.25[0.1-0.6]$; Fig. 2c). It may lead to $75 \%$ reduction in re-bleeding rate in patients who use PPI after endoscopic therapy in RCTs. As expected, RCTs retain better heterogeneity than observational studies ( $I^{2} 0$ vs. $47.8 \%$ ).

PPI in Variceal Bleeding c Sub-analysis depended on different research design methods. d Sub-analysis according to the duration of PPI administration; short-term use was defined as using $<10$ days and long-term use was $>4$ weeks. Weights are from random effects analysis. RCT, randomization controlled trial.

(Figure continued on next page.)

According to the duration of PPI use defined in registration studies, we manually classified the PPI use into short-term use ( $<10$ days), and long-term use ( $>4$ weeks). In conclusion, we speculated that long-term use of PPI after endoscopic procedure was recommended (pooled OR 0.47, 95\% CI 0.26-0.84, $p<0.05$; Fig. 2d). Administra- 


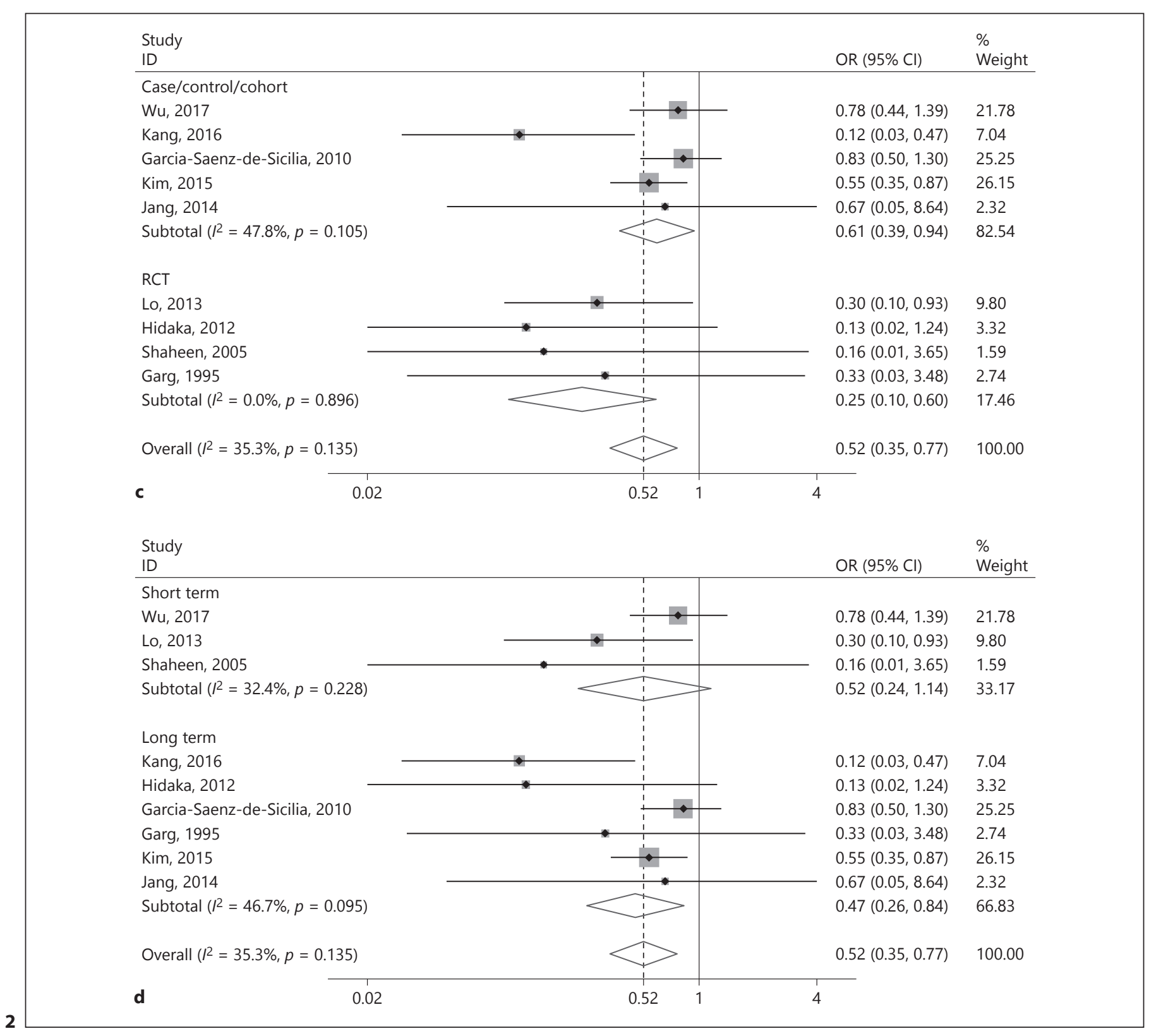

tion of PPI $<10$ days may not reduce the re-bleeding rate then (pooled OR $0.52,95 \%$ CI $0.24-1.14, p=0.11$ ). The effect of PPI use between 10 days and 4 weeks should be evaluated in the future. Meanwhile, exactly duration of PPI usage also concerns.

Sensitivity Analysis and Publication Bias

The funnel plot for possible publication bias demonstrated asymmetrical on visual inspection and confirmed by Egger's asymmetry test ( $p=0.046$; Fig. 3 ). We performed nonparametric "trim-and-fill" test through ran- dom-effects model for sensitivity analysis. Additionally, the conclusion in our analysis was robust (data not shown).

Association between PPI and Re-bleeding-Related Mortality

There were 6 researches that revealed the association between PPI and re-bleeding-related short-term mortality. We defined the short-term mortality as deceased of $<90$ days after index hospitalization, and long-term mortality was $>90$ days or estimated as overall death rate. We found PPI use cannot improve patients' short-term sur- 


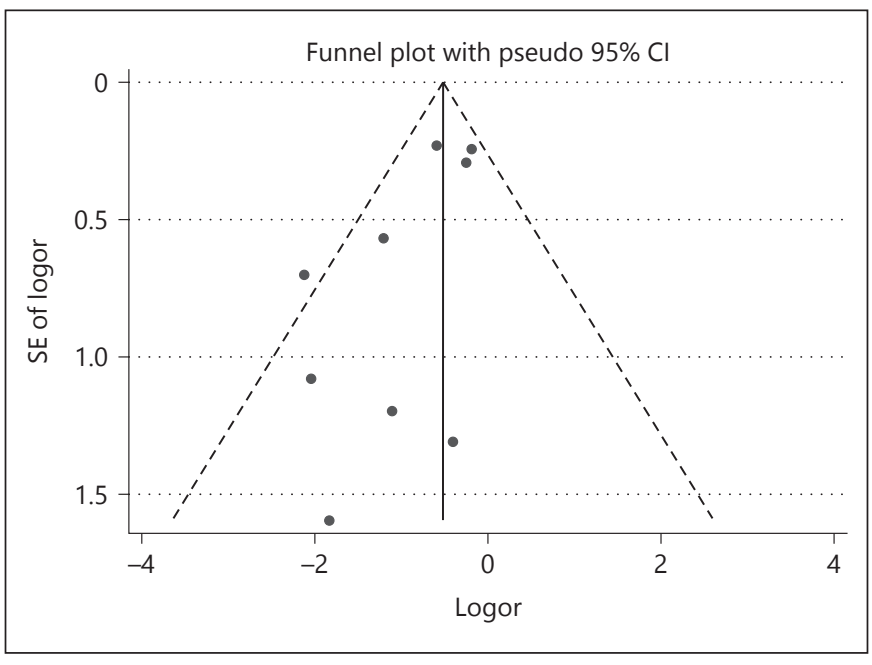

Fig. 3. Funnel plot of plausible publication bias.

vival rate after EGVB (the pooled OR $0.93,95 \%$ CI $0.23-$ $3.85, \mathrm{Z}=0.1, p=0.92$; Fig. 4a). Furthermore, PPI use was not related with long-term mortality in cirrhotics with history of variceal bleeding neither. The pooled OR was 1.67 (95\% CI 0.44-6.31, Z = 0.75, $p=0.45$; Fig. 4b). However, there were only 3 articles involved which should be concerned with caution.

\section{Association between PPI and Patients'}

Uncomfortable Complaints

Patients might feel chest pain, abdominal pain, chest tightness or dysphagia because of O-ring band trusses or ischemia. Among them, chest pain and dysphagia were most common in our experience. There were only 4 articles mentioned patients' complaints after endoscopic procedure. One RCT [9] documented a significant decrease of the adverse events incidence in patient with PPI and vasoconstrictor group (6\%) rather than group with vasoconstrictor only (55\%). Moreover, PPI use was associated with decreasing the incidence of chest pain (OR $0.05,95 \%$ CI $0.00-0.96, p<0.05$ ) in their study [9]. Unfortunately, no other data displayed in their publications implied PPI use will improve patients' uncomfortable complaints. Details showed in Table 2.

\section{Discussion}

To our knowledge, PPI is widely used in peptic ulcer, gastroesophageal reflux disease and dyspepsia. However, its robust and rapid antacid efficacy with minor side ef- fects has led to inappropriate use and abuse these days. Overuse of PPI may induce Clostridium difficile infection [24], pneumonia and menopausal fracture [25]. Furthermore, our previous research has confirmed that PPI use in cirrhotic patients with ascites will increase the risk of spontaneous bacterial peritonitis (not published yet). Although there are no consensuses about PPI use in EGVB, lots of physicians administrate PPI in the circumstance of upper gastrointestinal hemorrhage in cirrhotics empirically. The role of PPI in EGVB has been taken into consideration over decades. A review in 2008 addressed PPI overuse in cirrhosis might be empirical rather than evidence-based practice [13]. However, they also stated that the evidence for roles of PPI in varices bleeding was scarce at that time. Since then, although many number of relevant researches have been published, there was only one meta-analysis published to assess the role of PPI in cirrhotic patients with EGVB [14]. However, they found out PPI was only effective in cirrhotic patients who performed EVL for prophylaxis of variceal bleeding, rather than in urgent treatment or in other endoscopic managements.

This is the most comprehensive meta-analysis to evaluate the association between PPI and EGVB in liver cirrhosis patients. In the current meta-analysis, a total of 1,818 cirrhotic patients from 11 studies were involved. And 9 of them provided the information about PPI use and re-bleeding rate. Six articles investigated the association between PPI and bleeding-related mortality.

The overall estimate in this meta-analysis explored that PPI has a protective effect to prevent secondary bleeding after EVL or GVO. It may decrease post-procedure re-bleeding rate by almost $50 \%$ (pooled OR 0.52 , $95 \%$ CI $0.35-0.77, p=0.001$ ). The conclusion is consistent with 3 previous studies $[8,9,19]$ while contrary to the others $[6,7,11,21-23]$. Furthermore, a controlled trial of 118 patients with acute bleeding from esophageal varices demonstrated PPI administration post-EVL may possess similar hemostasis efficacy with less side effects when compared to vasoconstrictor medication [9]. But the result should be further investigated. Although gastric varices hemorrhage $(\mathrm{GVH})$ is less common than esophageal varices hemorrhage, it tends to be more deleterious with a higher re-bleeding rate and greatly challenging management [26-30]. We sub-analyzed the studies regarding esophageal varices hemorrhage and GVH with respect to different hemorrhage sites. It turns out that PPI plays a protective role despite of bleeding locations. 


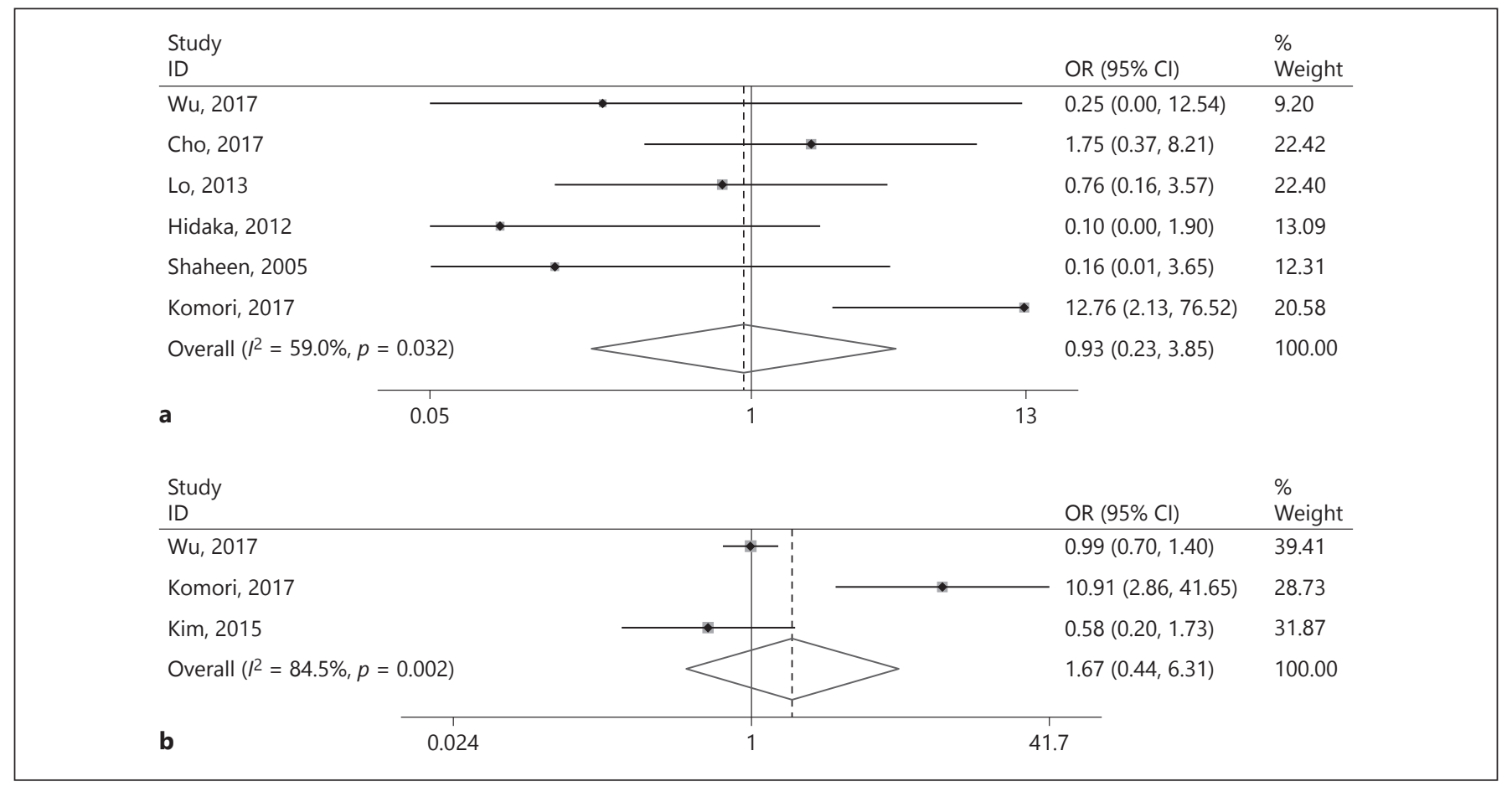

Fig. 4. Forest plots about related mortality of PPI administration after endoscopic therapy in cirrhotics with gastroesophageal variceal bleeding. a There were 6 studies that unveiled the association between PPI and re-bleeding-related short-term mortality $(\leq 90$ days). b Three studies involved have investigated the association between PPI and related long-term mortality ( $>90$ days or overall death rate). Weights are from random effects analysis.

which may explain the occurrence of gastric ulceration $[34,35]$. Moreover, exposure to gastric acid fluid may accelerate the ulceration progress [21]. That may be the underlying mechanism by which acid suppression can reduce or delay re-bleeding in GVH. A randomized control study from Japan revealed that compared with $\mathrm{H}_{2}$ receptor, PPI could improve the mean value of esophageal $\mathrm{pH}$ after sclerotherapy and maintain the overall $\mathrm{pH}$ $>4.0$ [36]. They also demonstrated a significant reduction in the time required for post-sclerotherapy ulcer healing in PPI administrated group $(p<0.05)$. The conclusion is consistent with the hypothesis mentioned above.

As mentioned above, PPI overuse is always a big problem around the world. In the light of safety and cost-effectiveness, standardizing the use of PPI is imperative. In literature, short-term (10 days) administration of PPI after EVL may reduce ulcer size [12, 21]. However, Young et al. [37] highlighted that post-EVL ulceration would be resolved in $14.4 \pm 1.4$ days. Similarly, we speculated that short-term use of PPI might be insufficient to heal the endoscopic hemostasis-related ulceration. Our analysis found that only using PPI 
Table 2. PPI use after endoscopic hemostasis was not associated with improvement of patients' uncomfortable complaints and ulcer incidence, but may decrease the size of ulceration in some extent

\begin{tabular}{|c|c|c|c|c|c|c|c|c|c|c|c|c|c|c|c|c|}
\hline \multirow{2}{*}{$\begin{array}{l}\text { Author, } \\
\text { year }\end{array}$} & \multirow{2}{*}{$\begin{array}{l}\text { Endoscopic } \\
\text { therapy }\end{array}$} & \multicolumn{3}{|c|}{ Ulcer incidence } & \multicolumn{3}{|l|}{ Ulcer size } & \multicolumn{3}{|c|}{ Ulcer healing time } & \multicolumn{3}{|c|}{ Chest pain } & \multicolumn{3}{|c|}{ Dysphagia } \\
\hline & & $\begin{array}{l}\text { PPI } \\
\text { group }\end{array}$ & $\begin{array}{l}\text { non-PPI } \\
\text { group }\end{array}$ & $p$ value & $\begin{array}{l}\text { PPI } \\
\text { group }\end{array}$ & $\begin{array}{l}\text { non-PPI } \\
\text { group }\end{array}$ & $p$ value & $\begin{array}{l}\text { PPI } \\
\text { group }\end{array}$ & $\begin{array}{l}\text { non-PPI } \\
\text { group }\end{array}$ & $p$ value & OR & $95 \%$ CI & $p$ value & OR & $95 \%$ CI & $p$ value \\
\hline $\begin{array}{l}\text { Garg et al. } \\
{[23], 1995}\end{array}$ & Sclerotherapy & $16 / 21$ & $18 / 23$ & 0.70 & - & - & - & - & - & - & 0.38 & $0.07-2.21$ & 0.42 & 0.58 & $0.17-2.01$ & 0.58 \\
\hline $\begin{array}{l}\text { Lo et al. } \\
{[9], 2013}\end{array}$ & EVL & $14 / 22$ & $18 / 21$ & 0.09 & $1 / 22^{\dagger}$ & $6 / 21^{\dagger}$ & 0.04 & - & - & - & 0.05 & $0.00-0.96$ & 0.003 & NA & NA & NA \\
\hline $\begin{array}{l}\text { Shaheen } \\
\text { et al. [21], } \\
2005\end{array}$ & EVL & $2.18(0.2)^{\ddagger}$ & $2.25(0.31)^{\ddagger}$ & 0.85 & $82(22)^{\S}$ & $37(9)^{\S}$ & 0.01 & - & - & - & 2.86 & $0.11-74.37$ & 1.0 & 3.16 & $0.30-33.09$ & 0.61 \\
\hline $\begin{array}{l}\text { Hidaka } \\
\text { et al. [6], } \\
2012\end{array}$ & EVL & - & - & - & - & - & - & - & - & - & NA & NA & NA & 0.80 & $0.18-3.5$ & 1.0 \\
\hline $\begin{array}{l}{ }^{\dagger} \text { The } \mathrm{n} \\
{ }^{\star} \text { The ir } \\
\text { § The u } \\
\text { EVL, es }\end{array}$ & $\begin{array}{l}\text { number of ulcer } \\
\text { ncidence of ulce } \\
\text { llcer size which } \\
\text { sophageal varic }\end{array}$ & $\begin{array}{l}\text { size which } \\
\text { eration whic } \\
\text { performed } \\
\text { eal ligation; }\end{array}$ & $\begin{array}{l}\text { was }>1.5 \mathrm{~cm} \text {, } \\
\text { hh was adjuste } \\
\text { the endoscopi } \\
\mathrm{NA} \text {, not avail }\end{array}$ & $\begin{array}{l}\text { showed } \\
\text { ed for nu } \\
\text { ic proce } \\
\text { llable; PP }\end{array}$ & $\begin{array}{l}\mathrm{n} / \mathrm{N} \text {. } \\
\text { ber of ban } \\
\text { re in day } \\
\text { proton pu }\end{array}$ & $\begin{array}{l}\text { nds placec } \\
10 \text { after E } \\
\text { ump inhil }\end{array}$ & $\begin{array}{l}\text { showed } \\
\text { L, showe } \\
\text { tor. }\end{array}$ & $\begin{array}{l}\mathrm{mm}^{2} \text {, } \\
\text { by } \mathrm{mn}\end{array}$ & $\begin{array}{l}\text { nean (SE). } \\
\text { mean (SE) }\end{array}$ & & & & & & & \\
\hline
\end{tabular}

$>4$ weeks may decrease re-bleeding rate. The effect of PPI use between 10 days and 4 weeks still remains uncertain. Further researches should be conducted to determine the optimal duration of PPI usage after endoscopic therapy.

Unlike previous meta-analysis [14], our study has overturned the conclusion that acid suppression therapy was only effective in patients who underwent EVL for prophylaxis of variceal bleeding. We found PPI use can decrease the re-bleeding rate after EVL or GVO on both prophylaxis and urgent treatment purpose. In conclusion, PPI administration (at least of 4 weeks) is recommended in EGVB irrespective of bleeding locations or treatment purposes.

In order to explain the possible moderate heterogeneity in our results, we subsequently analyzed the studies through design methods. There were 4 RCTs, 4 retrospective cohort studies, and 1 case-control study in our rebleeding rate analysis. We categorized the group into RCTs and observational studies, to eliminate the potential bias. Both of them stated the evidence that PPI is beneficial for preventing secondary bleeding after endoscopic procedure. As expected, observational studies have a moderate heterogeneity (47.8\%), which is higher than RCTs $(0 \%)$. The heterogeneity might be associated with selection bias and recall bias.

We also analyzed 6 articles which provided the data about PPI use, short-term re-bleeding-related mortality and long-term mortality. Neither of them was associated with PPI use. A small size case-control study found that
PPI use increased the short-term and long-term bleedingrelated mortality [38]. However, the remaining researches failed to find that PPI was associated with bleedingrelated mortality. The mortality of liver cirrhosis may result from prophylactic administration of antibiotics [38], bacterial infection [39], Child-Pugh classification, $\beta$ blocker use, and the severity of hemorrhage [8]. Interestingly, Kim et al. [8] supported our opinion that prophylactic use of PPI could reduce re-bleeding, but not associated with bleeding-related death. But their conclusion was only limited to patients undergoing GVO.

Although PPI can decrease the re-bleeding rate, it is not associated with re-bleeding-related mortality; we suppose that PPI should not be used as the unique rescue therapy during re-bleeding episode. Endoscopic hemostasis or transjugular intrahepatic portosystemic shunt is still the first-line therapy, if necessary.

\section{Limitation}

There are several limitations to our present research:

1. Almost all population involved in our study were Orientals, and we didn't search literature in other language because of our language limitation. Selection bias might be existed. The conclusion should be taken with caution when applied to general population.

2. The data relative to post-procedure induced ulceration, ulcer healing time and patients' uncomfortable complaints (like chest pain and dysphasia) were 
scarce. It interfered with our analysis when investigating the relationship between PPI and ulcer sizes, ulceration healing time or adverse events. Some literature have documented that PPI could reduce ulcer sizes [9, 21]. Meanwhile, Lo et al. [9] concluded PPI would improve the complaints like chest pain and abdominal pain. However, within the limited data, we thought PPI use might not decrease the incidence of ulceration, and it was not robust to consider that PPI could significantly improve patients' uncomfortable complaints, such as chest pain [21, $23]$ or dysphagia $[6,23]$. Since repeated endoscopy procedures after hemostasis may cause secondary trauma to patients, and most adverse events were transient, further researches may not be necessary in this issue. However, it is still necessary to explore the underlying mechanism about PPI and their role in ulceration.

3. The dosage and therapy duration of PPI differs among these researches. The efficacy of different dosage of PPI in hemostasis is undetermined. Long-term use of PPI may lead to other complications in cirrhotic patients. Thus, more researches concerning about dosage of PPI are warranted in the future.

4. Given that all 3 researches assessing the long-term mortality were observational studies, selection biases, recall bias and other confounding factors may exist. As abovementioned, long-term use of PPI increases the incidence of Clostridium difficile infection, pneumonia, menopausal fracture, spontaneous bacterial peritonitis and hepatic encephalopathy in liver cirrhosis. Therefore, the conclusion that PPI use is not associated with long-term mortality in EGVB patients should be extrapolated with caution. More precise and headto-head researches should be taken into consideration.

\section{Conclusion}

In conclusion, PPI is widely used in our clinical practice, and its abuse and inappropriate use problem have arisen. Although, there are no related guidelines recommending routine PPI usage during the process of EGVB, we believe PPI use (at least 1 month) in the course of EGVB would decrease the re-bleeding rate by acid suppression and promotion of ulcer healing. Moreover, PPI use is both effective in prophylaxis and emergency treatment procedures. However, PPI use, no matter how long it takes, is not associated with bleeding-related mortality so far. Endoscopic hemostasis or transjugular intrahepatic portosystemic shunt is still the first-line therapy if necessary.

\section{Acknowledgment}

None.

\section{Disclosure Statement}

The authors have no conflicts of interest to disclose.

\section{Funding Sources}

There are no funding sources to declare.

\section{Author Contributions}

L.L. and B.C. screened the literature from database. The quality of enrolling studies and statistical analysis was assessed independently by Y.D. and X.J. Thesis writing and modification were completed by L.L., W.L., and C.S. Proofreading was performed by C.S.

\section{References}

1 Angeli P, Bernardi M, Villanueva C, Francoz C, Mookerjee RP, Trebicka J, et al.; European Association for the Study of the Liver. Electronic address: easloffice@easloffice.eu; European Association for the Study of the Liver. EASL Clinical Practice Guidelines for the management of patients with decompensated cirrhosis. J Hepatol. 2018 Aug;69(2): 406-60.

2 Tripathi D, Stanley AJ, Hayes PC, Patch D, Millson C, Mehrzad H, et al.; Clinical Services and Standards Committee of the British Society of Gastroenterology. U.K. guidelines on the management of variceal haemorrhage in cirrhotic patients. Gut. 2015 Nov;64(11): 1680-704.

3 Garcia-Pagán JC, Bosch J. Endoscopic band ligation in the treatment of portal hypertension. Nat Clin Pract Gastroenterol Hepatol. 2005 Nov;2(11):526-35.

4 Vanbiervliet G, Giudicelli-Bornard S, Piche T, Berthier F, Gelsi E, Filippi J, et al. Predictive factors of bleeding related to post-banding ulcer following endoscopic variceal ligation in cirrhotic patients: a case-control study. Aliment Pharmacol Ther. 2010 Jul;32(2):225-32.

5 Nijhawan S, Rai RR, Nepalia S, Pokharana DS, Bharagava N. Natural history of postligation ulcers. Am J Gastroenterol. 1994 Dec;89(12): 2281-2.

6 Hidaka H, Nakazawa T, Wang G, Kokubu S, Minamino T, Takada J, et al. Long-term administration of PPI reduces treatment failures after esophageal variceal band ligation: a randomized, controlled trial. J Gastroenterol. 2012 Feb;47(2):118-26.

7 Jang WS, Shin HP, Lee JI, Joo KR, Cha JM, Jeon JW, et al. Proton pump inhibitor administration delays rebleeding after endoscopic gastric variceal obturation. World J Gastroenterol. 2014 Dec;20(45): 17127-31. 
8 Kim KR, Jun CH, Cho KM, Wi JW, Park SY, Cho SB, et al. Can proton pump inhibitors reduce rebleeding following Histoacryl sclerotherapy for gastric variceal hemorrhage? Korean J Intern Med (Korean Assoc Intern Med). 2015 Sep;30(5):593-601.

9 Lo GH, Perng DS, Chang CY, Tai CM, Wang HM, Lin HC. Controlled trial of ligation plus vasoconstrictor versus proton pump inhibitor in the control of acute esophageal variceal bleeding. J Gastroenterol Hepatol. 2013 Apr; 28(4):684-9.

10 Cho E, Jun CH, Cho SB, Park CH, Kim HS, Choi SK, et al. Endoscopic variceal ligationinduced ulcer bleeding: what are the risk factors and treatment strategies? Medicine (Baltimore). 2017 Jun;96(24):e7157.

11 Garcia-Saenz-de-Sicilia M, Sanchez-Avila F, Chavez-Tapia NC, Lopez-Arce G, Garcia-Osogobio S, Ruiz-Cordero R, et al. PPIs are not associated with a lower incidence of portalhypertension-related bleeding in cirrhosis. World J Gastroenterol. 2010 Dec;16(46): 5869-73.

12 Lo EA, Wilby KJ, Ensom MH. Use of proton pump inhibitors in the management of gastroesophageal varices: a systematic review. Ann Pharmacother. 2015 Feb;49(2):207-19.

13 Lodato F, Azzaroli F, Di Girolamo M, Feletti V, Cecinato P, Lisotti A, et al. Proton pump inhibitors in cirrhosis: tradition or evidence based practice? World J Gastroenterol. 2008 May;14(19):2980-5.

14 Zhu J, Qi X, Yu H, Su C, Guo X. Acid suppression in patients treated with endoscopic therapy for the management of gastroesophageal varices: a systematic review and meta-analysis. Expert Rev Gastroenterol Hepatol. 2018 Jun;12(6):617-24.

15 Wells G, Shea B, O'Connell D, Peterson J, Welch V, Losos M, Tugwell P. The NewcastleOttawa Scale (NOS) for assessing the quality of nonrandomised studies in meta-analyses. http://wwwohrica/programs/clinical_epidemiology/oxfordasp.

16 Higgins JP, Altman DG, Gøtzsche PC, Jüni P, Moher D, Oxman AD, et al.; Cochrane Bias Methods Group; Cochrane Statistical Methods Group. The Cochrane Collaboration's tool for assessing risk of bias in randomised trials. BMJ. 2011 Oct;343:d5928.
17 Higgins JP, Thompson SG, Deeks JJ, Altman DG. Measuring inconsistency in meta-analyses. BMJ. 2003 Sep;327(7414):557-60.

18 Egger M, Davey Smith G, Schneider M, Minder C. Bias in meta-analysis detected by a simple, graphical test. BMJ. 1997 Sep;315(7109): 629-34.

19 Kang SH, Yim HJ, Kim SY, Suh SJ, Hyun JJ, Jung SW, et al. Proton Pump Inhibitor Therapy Is Associated With Reduction of Early Bleeding Risk After Prophylactic Endoscopic Variceal Band Ligation: A Retrospective Cohort Study. Medicine (Baltimore). 2016 Feb; 95(8):e2903.

20 Komori K, Kubokawa M, Ihara E, Akahoshi K, Nakamura K, Motomura K, et al. Prognostic factors associated with mortality in patients with gastric fundal variceal bleeding. World J Gastroenterol. 2017 Jan;23(3):496-504.

21 Shaheen NJ, Stuart E, Schmitz SM, Mitchell KL, Fried MW, Zacks S, et al. Pantoprazole reduces the size of postbanding ulcers after variceal band ligation: a randomized, controlled trial. Hepatology. 2005 Mar;41(3):588-94.

22 Wu CK, Liang CM, Hsu CN, Hung TH, Yuan LT, Nguang SH, et al. The Role of Adjuvant Acid Suppression on the Outcomes of Bleeding Esophageal Varices after Endoscopic Variceal Ligation. PLoS One. 2017 Jan;12(1): e0169884.

23 Garg PK, Sidhu SS, Bhargava DK. Role of omeprazole in prevention and treatment of postendoscopic variceal sclerotherapy esophageal complications. Double-blind randomized study. Dig Dis Sci. 1995 Jul;40(7):1569-74.

24 Naito Y, Kashiwagi K, Takagi T, Andoh A, Inoue R. Intestinal Dysbiosis Secondary to Proton-Pump Inhibitor Use. Digestion. 2018; 97(2):195-204.

25 Eom CS, Lee SS. Risk of fracture and pneumonia from acid suppressive drugs. World J Methodol. 2011 Sep;1(1):15-21.

26 Sarin SK, Lahoti D, Saxena SP, Murthy NS, Makwana UK. Prevalence, classification and natural history of gastric varices: a long-term follow-up study in 568 portal hypertension patients. Hepatology. 1992 Dec;16(6):13439.

27 de Franchis R, Primignani M. Natural history of portal hypertension in patients with cirrhosis. Clin Liver Dis. 2001 Aug;5(3):645-63.
28 Trudeau W, Prindiville T. Endoscopic injection sclerosis in bleeding gastric varices. Gastrointest Endosc. 1986 Aug;32(4):264-8.

29 Kim T, Shijo H, Kokawa H, Tokumitsu H, Kubara K, Ota K, et al. Risk factors for hemorrhage from gastric fundal varices. Hepatology. 1997 Feb;25(2):307-12.

30 Hosking SW, Johnson AG. Gastric varices: a proposed classification leading to management. Br J Surg. 1988 Mar;75(3):195-6.

31 Xu L, Ji F, Xu QW, Zhang MQ. Risk factors for predicting early variceal rebleeding after endoscopic variceal ligation. World J Gastroenterol. 2011 Jul;17(28):3347-52.

32 Macdougall BR, Williams R. A controlled clinical trial of cimetidine in the recurrence of variceal hemorrhage: implications about the pathogenesis of hemorrhage. Hepatology. 1983 Jan-Feb;3(1):69-73.

33 Ahmed AM, al Karawi MA, Shariq S, Mohamed AE. Frequency of gastroesophageal reflux in patients with liver cirrhosis. Hepatogastroenterology. 1993 Oct;40(5):478-80.

34 Kunstlinger F, Brunelle F, Chaumont P, Doyon D. Vascular occlusive agents. AJR Am J Roentgenol. 1981 Jan;136(1):151-6.

35 Woodward SC, Herrmann JB, Cameron JL, Brandes G, Pulaski EJ, Leonard F. Histotoxicity of Cyanoacrylate Tissue Adhesive in the Rat. Ann Surg. 1965 Jul;162:113-22.

36 Akahoshi T, Kawanaka H, Tomikawa M, Saeki H, Uchiyama H, Ikeda T, et al. Effect of proton pomp inhibitor (PPI : Rabeprazole) on reflux esophagitis after endoscopic injection sclerotherapy (EIS), a randomized control study (24 hour-pH monitoring). Fukuoka Igaku Zasshi. 2013 Dec;104(12):483-9.

37 Young MF, Sanowski RA, Rasche R. Comparison and characterization of ulcerations induced by endoscopic ligation of esophageal varices versus endoscopic sclerotherapy. Gastrointest Endosc. 1993 Mar-Apr;39(2):119-22.

38 Komori K, Kubokawa M, Ihara E, Akahoshi K, Nakamura K, Motomura K, et al. Prognostic factors associated with mortality in patients with gastric fundal variceal bleeding. World J Gastroenterol. 2017 Jan;23(3):496504

39 Goulis J, Patch D, Burroughs AK. Bacterial infection in the pathogenesis of variceal bleeding. Lancet. 1999 Jan;353(9147):139-42. 